\title{
Bacterial strategies to overcome insect defences
}

\begin{abstract}
Isabelle Vallet-Gely*, Bruno Lemaitre ${ }^{* \ddagger}$ and Frédéric Boccard*
Abstract | Recent genetic and molecular analyses have revealed how several strategies enable bacteria to persist and overcome insect immune defences. Genetic and genomic tools that can be used with Drosophila melanogaster have enabled the characterization of the pathways that are used by insects to detect bacterial invaders and combat infection. Conservation of bacterial virulence factors and insect immune repertoires indicates that there are common strategies of host invasion and pathogen eradication. Long-term interactions of bacteria with insects might ensure efficient dissemination of pathogens to other hosts, including humans.
\end{abstract}

\section{Persistence \\ The survival of bacteria in large numbers in a host.}

* Centre de Génétique Moléculaire du CNRS, Gif-sur-Yvette, France. ${ }^{\ddagger}$ Global Health Institute, École Polytechnique Fédérale de Lausanne, Lausanne, Switzerland. Correspondence to F.B. e-mail: boccard@cgm. cnrs-gif.fr

doi: 10.1038 /nrmicro 1870 Published online 10 March 2008
Insects are the most diverse group of animals on Earth, with over a million described species - more than all of the other animal groups combined. Insects can be found in almost all environments. Like other metazoans, insects can be infected by viruses, bacteria, fungi and parasites, but surprisingly little is known about the molecular mechanisms of infection ${ }^{1}$. Historically, economically motivated studies of sicknesses in domesticated insects, such as silkworm or honeybees, have dominated the field. For example, the French government commissioned Louis Pasteur to find a cure for a silkworm epizootic that was threatening the silk industry in 1865. Pasteur managed to identify the parasite that was causing the epidemic (Nosema bombycis, a microsporidia that is found in the haemolymph and is transmitted vertically) and his recommendations saved the silk industry. Another factor that has motivated studies of entomopathogenic microorganisms is the need to develop strategies that are based on microbial pathogens to eradicate pest insects ${ }^{2}$.

The awareness that the dissemination of microorganisms by insects could pose a serious threat to human or animal health revived interest in microorganism-insect interactions. Previously, it had been assumed that insects were passive vectors that could transmit microorganisms by three non-specific interactions: carriage on the body, regurgitation and defecation. Today, most researchers think that dissemination of pathogens by vectors might involve specific interactions between the host and the bacteria. Therefore, studying the mechanisms that ensure persistence and transmission of microorganisms might allow the development of strategies to prevent infectious diseases. More recently, model systems for host-pathogen interactions have been used to dissect the crosstalk between the partners ${ }^{3-5}$, and the tractability of Drosophila melanogaster to genetic and genomic analyses have made it a popular insect model ${ }^{6}$.

Insects inhabit diverse niches and interact with various bacteria to form relationships that range from mutualistic symbiosis to pathogenesis. Insects have specific features that protect them from pathogens. Their first lines of defence are physical barriers (FIG. 1), including the cuticle, that protect host cells and tissues from the external environment. Although fungi, such as Beauveria bassiana, can breach the cuticle ${ }^{7}$, this strategy has not been reported for bacterial pathogens. The introduction of bacteria into haemolymph can occur after wounding by injury, invasive pathogens, parasitoids or predators. Sepsis can also be caused by nematodes that penetrate the insect body through the mouth, anus or the spiracles. Insects can also harbour bacterial pathogens, such as Wolbachia and Spiroplasma species, that are gametetransmitted and that colonize only female progeny, killing male hosts. The main route of interaction between insects and bacteria seems to be through the ingestion of contaminated food. Larvae or adult insects feed on decaying fruits or animal cadavers that can contain up to $10^{11}$ bacteria per $\mathrm{ml}$. Unlike mammals, pathogen infection through respiratory systems has not been reported in insects.

In this Review we describe the crosstalk that exists between bacteria and insects. In particular we discuss the strategies that are used by bacterial pathogens to persist in insects and the responses of insects to such infections. Positive symbiotic interactions have been reviewed elsewhere ${ }^{8,9}$ and will not be considered here. The strategies discussed here include the interactions between: 


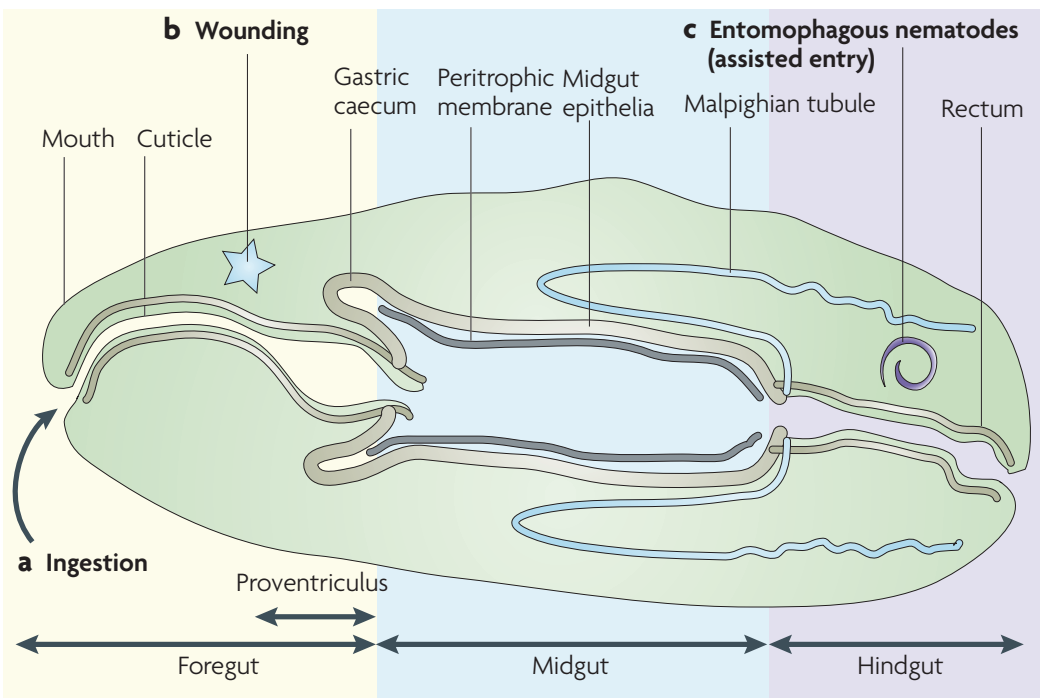

Figure 1 | Main routes of bacterial infection in insects. The different physical barriers that ensure protection from infection by pathogens are shown for a model insect. a | Ingestion. The different parts of the insect gut are shown. The foregut and hindgut are covered by cuticle, whereas the midgut epithelium is protected from ingested bacteria by the peritrophic membrane. $\mathbf{b}$ |Wounding. Direct entry of bacteria in the insect haemocoel can occur after breaching of the cuticle. c|Assisted entry. Bacteria, such as Photorhabdus and Xenorhabdus sp., can be delivered into the insect body cavity by entomophagous nematodes.

Colonization

The ability to multiply in the host.

Innate immunity

Effector mechanisms that control infection and that possess a certain degree of specificity to different classes of microorganisms.
Yersinia pestis with Xenopsylla cheopis (Siphonaptera; fleas); Photorhabdus species and Xenorhabdus species with Manduca sexta (Lepidoptera; moths and butterflies); Bacillus thuringiensis or Bacillus cereus with various insect orders; Serratia entomophila with the grass grub Costelytra zealandica (Coleoptera); and Erwinia carotovora, Pseudomonas entomophila and Serratia marcescens with Drosophila spp. (Diptera). Other interactions (TABLE 1) have been reviewed elsewhere ${ }^{1,10,11}$, but these infections will not be discussed here because of a lack of detailed molecular or genetic information.

\section{Ingestion of microorganisms}

Ingestion of bacteria by insects might have important consequences: several reports have described transmission of bacteria by houseflies ${ }^{12}$ (Diptera), sometimes more than two weeks after feeding ${ }^{13,14}$, and cockroaches (Dictyoptera) might be vectors for nosocomial infections ${ }^{15}$. A remarkable case of oral infection occurs when fleas feed on rodents that are infected by Y. pestis; the fleas become plague vectors, as $Y$. pestis can colonize the flea gut ${ }^{16}$.

The insect gut is a continuous tube that runs from the mouth to the anus ${ }^{17}$. The alimentary canal is divided into three regions: the foregut, the midgut and the hindgut. The foregut and the hindgut are of ectodermal origin and are therefore covered by a cuticle that is continuous to the external one. The midgut is of endodermal origin and is not lined by a cuticle; it comprises an epithelium layer that is bordered by a peritrophic membrane on its luminal surface (FIG. 1). The peritrophic membrane forms a barrier between the epithelial layer and the midgut lumen, which contains the food bolus. Circular and longitudinal muscles are responsible for peristalsis. The insect proventriculus is a remarkable foregut organ that is located at the border between the foregut and midgut. Its morphology is variable, but it can form a simple valve at the entrance of the midgut. In various insect species, such as cockroaches, beetles (Coleoptera) and fleas, the proventriculus is a grinding apparatus with strong cuticular plates that can break up food ${ }^{17}$. Circular muscles surround the proventriculus, which can also be an immuno-reactive organ, for example in D. melanogaster ${ }^{18}$ and Tsetse flies ${ }^{19}$ (Diptera). Colonization of this organ by bacteria plays an important role in the interaction of $Y$. pestis with fleas ${ }^{20}$ (see below).

Elimination of bacteria from the gut. Ingested microorganisms are transferred passively with food through the mouth to the posterior part of the foregut, and then actively transported by peristalsis through the midgut. The conditions of the midgut lumen can inhibit growth or kill ingested microorganisms. Indeed, in most cases, ingested bacteria cannot trigger the production of antimicrobial peptides (AMP) or cause insect death. To persist, it is generally assumed that microorganisms must survive the $\mathrm{pH}$, digestive enzymes, redox potential and ionic strength of the midgut. The epithelial innate immune system might produce sufficient amounts of reactive oxygen species (ROS) to kill ingested pathogens (FIG. 2). Indeed, ROS-dependent protection against ingested microorganisms might constitute the first line of inducible defence in $D$. melanogaster. The ingestion of bacteria results in an increase in ROS that is synthesized by the NADPH oxidase enzyme dDuox ${ }^{21}$. Adult flies in which dDuox expression was silenced by RNA interference showed a marked increase in their mortality rate after ingestion of food that was contaminated with microorganisms; ingested bacteria were shown to persist and proliferate throughout the intestinal tract of flies when dDuox expression was silenced. This indicates that bacteria have to resist the epithelial oxidative burst in order to persist. Moreover, the expression of the antioxidant gene katN (a non-haem catalase) in Salmonella or Escherichia coli spp. allows these bacteria to persist and to trigger AMP production ${ }^{22}$. Futhermore, as in mammals, an antioxidant system that comprises an extracellular immune-regulated catalase is used by $D$. melanogaster to maintain the homeostatic redox balance that is perturbed by the ingestion of microorganisms ${ }^{22}$.

Bacterial persistence in the gut. Only a handful of bacteria can persist in large numbers in the digestive tract of insects. It is generally assumed that most ingested bacteria are eliminated by ROS, by peristalsis or by other unknown mechanisms. Some bacteria, such as Mycobacterium ulcerans, ensure proliferation by moving from the digestive tract to another organ (BOX 1). The persistence of bacteria can result in established colonization of the insect midgut (FIG. 3), facilitating transmission of bacteria to other hosts.

A striking example of bacterial survival in an insect gut is the interaction between the plague bacillus and the flea $^{16}$. Y. pestis is endemic among wild rodents, and fleas 
Table 1 | Examples of interactions between bacteria and insects

\begin{tabular}{|c|c|c|c|}
\hline Bacteria & Type of interaction & Host (mode of interaction) & References \\
\hline Erwinia aphidicola & Pathogen & Pea aphid (ingestion) & 113 \\
\hline Dickeya dadantii & Pathogen & Pea aphid (ingestion) & 78 \\
\hline Pseudomonas entomophila & Pathogen & Drosophila, Bombyx, Galleria (ingestion) & 31 \\
\hline Yersinia pestis & Pathogen & Rat flea (ingestion) & 16 \\
\hline Serratia entomophila & Pathogen & Grass grub (ingestion) & 38 \\
\hline Serratia marcescens & Pathogen & Drosophila (ingestion) & 33 \\
\hline Photorhabdus sp. & Pathogen & Lepidopteran (assisted entry) & 53 \\
\hline Xenorhabdus sp. & Pathogen & Lepidopteran (assisted entry) & 53 \\
\hline Vibrio cholerae & Pathogen & Drosophila (ingestion) & 32 \\
\hline Melissococcus pluton & Pathogen & Honey bee (ingestion) & 1 \\
\hline Bacillus thuringiensis & Pathogen & Different orders (ingestion) & 111 \\
\hline Bacillus papillae & Pathogen & Scarab larvae (ingestion) & 105 \\
\hline Paenibacillus lentimorbus & Pathogen & Scarab larvae (ingestion) & 105 \\
\hline Paenibacillus larvae & Pathogen & Honey bee larvae (ingestion) & 105 \\
\hline Bacillus sphaericus & Pathogen & Mosquito (ingestion) & 105 \\
\hline Bacillus laterosporus & Pathogen & Bee larvae, dipteran (ingestion) & 105 \\
\hline Pseudomonas aeruginosa & Opportunistic & Caterpillar (ingestion) & 10 \\
\hline Pseudomonas aeruginosa & Opportunistic & Drosophila (direct injection) & 58 \\
\hline Bacillus cereus & Opportunistic & Galleria mellonella (ingestion) & 114 \\
\hline Erwinia carotovora & Infectious & Drosophila larvae (ingestion) & 30 \\
\hline Shigella spp. & Passive vector & House fly (ingestion) & 1 \\
\hline Rickettsia spp. & Vector & Cat flea (ingestion) & 115 \\
\hline Bartonella spp. & Vector & Cat flea (ingestion) & 115 \\
\hline
\end{tabular}

become infected when they feed on these rodents. $Y$. pestis proliferates in the flea midgut and colonizes the proventriculus. This colonization renders fleas unable to pump blood into their midgut (so-called blocked fleas). Starvation that is induced by the proventriculus blockage results in repeated feeding attempts by the flea, thereby inducing multiple flea bites. Regurgitation of contaminated blood into the bite site transmits plague. Ultimately, proventriculus blockage kills the flea.

Survival in the flea midgut, which is an essential step for efficient colonization by Y. pestis, is due to a single plasmid-borne gene, named $y m t^{23}$ (Yersinia murine toxin). Introduction of ymt into other enterobacterial species enables them to colonize the flea midgut. The ymt gene encodes a phospholipase D enzyme that protects bacteria from a blood degradation product. Bacteria that lack $y m t$ are eliminated from $80-95 \%$ of fleas during the first 24 hours after ingestion. Interestingly, YMT does not have a role in proventriculus blocking, as colonization by $y m t$ mutants occurs in the proventriculus of fleas, not in the midgut.

The proventriculus blockage arises because of hemin storage $(\mathrm{hms})$ gene products ${ }^{24}$, which produce an extracellular matrix that is involved in biofilm formation, both in vitro and in the flea proventriculus ${ }^{20}$. Development of a biofilm might protect $Y$. pestis from the immune system $^{25}$. Y. pestis hms mutants still proliferate in the flea midgut, but cannot colonize the proventriculus ${ }^{26}$.
Another gene that is involved in flea blockage, gmhA, encodes a phosphoheptose isomerase that is involved in lipooligosaccharide synthesis, an essential component of the outer membrane in Y. pestis. Mutations in gmhA prevent the formation of biofilms that are required for proventriculus blockage ${ }^{27}$.

Bacteria also persist in D. melanogaster, which has been used as a model to study host-pathogen interactions between insects and bacteria. A few species can persist in the gut, trigger the immune response or are pathogenic $^{28-33}$. Most of the bacterial persistence mechanisms in D. melanogaster are unknown, but some clues have been identified using Erwinia carotovora subsp. carotovora 15. Erwinia species are phytopathogenic bacteria that can use D. melanogaster as a vector ${ }^{34,35}$. E. c. carotovora 15 can persist in the gut of D. melanogaster larvae and induce both a local and a systemic immune response. Activation of the immune response eradicates E. c. carotovora 15 from infected insects ${ }^{30}$. The evf (Erwinia virulence factor) gene is required for bacterial persistence ${ }^{36}$. Transfer of the evf gene to other Gram-negative bacteria allows them to persist in D. melanogaster, indicating that a single determinant can enable persistence of bacteria in a host ${ }^{36}$. Evf does not seem to be involved in detoxifying or neutralizing molecules that participate in bacterial clearance, such as ROS and AMP, or in reprogramming metabolic pathways that render the bacterial cells refractory to elimination ${ }^{37}$. The facts that evf mutants can survive as well as 

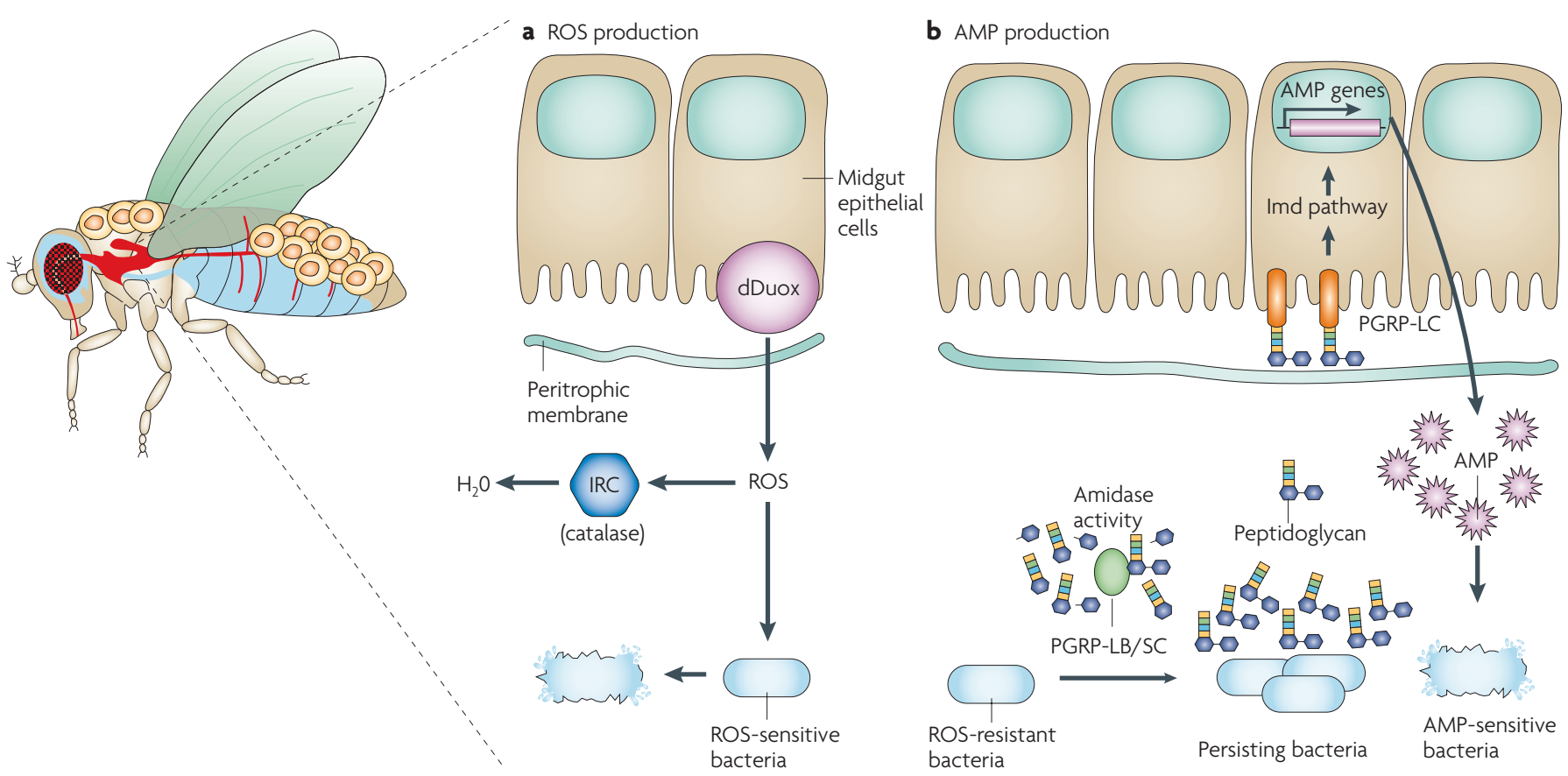

Figure 2 | Schematic diagram of local immune response in Drosophila. Bacteria in the gut trigger local production of reactive oxygen species (ROS; panel a) and antimicrobial peptides (AMPs; panel b), which are both inducible defence mechanisms. ROS are produced by the dDuox protein, and are detoxified by the immune-regulated catalase (IRC). If bacteria can resist the oxidative stress, they may be able to persist in the gut. Persisting bacteria release peptidoglycan fragments that are either detoxified by the amidase activity of some peptidoglycan recognition proteins PGRPs (PGRP-LB for instance), or serve as elicitors of the Imd pathway (upon recognition by PGRP-LC), which leads to AMP production. AMPs contribute to bacterial elimination from the gut. Modified with permission from REF. 93 (C) (2007) Annual Reviews.

E.c. carotovora 15 in isolated guts, and that evf-expressing bacteria allow persistence in trans of evf-deficient bacteria, supports the hypothesis that Evf perturbs the gut physiology, which would otherwise eradicate ingested bacteria ${ }^{37}$. Overexpression of evf results in massive bacterial accumulation in the gut and insect mortality. Interestingly, no lethality was observed after direct injection of such bacteria into the body cavity, which indicates that Evf-mediated persistence is specific to the physiology and architecture of the D. melanogaster larval gut ${ }^{36}$.

Another example of bacterial persistence in the gut is the 'amber disease', which affects the New Zealand grass grub and is caused by Serratia spp. ${ }^{38}$. Upon ingestion of S. entomophila, larvae cease feeding within 48 hours; their gut, which is normally dark, develops an amber coloration that results from gut clearance. In addition, levels of major digestive enzymes in the gut (such as trypsin) decrease sharply ${ }^{38}$ and larvae enter a long chronic phase during which they stop feeding. They can remain in this state for a prolonged period (1-3 months) before the infecting bacteria eventually invade the haemocoel and cause rapid death ${ }^{38,39}$. Two loci that are responsible for cessation of feeding and for gut clearance have been identified on a large $115-\mathrm{kb}$ plasmid, pADAP ${ }^{40,41}$. One locus, comprising 18 genes, is required for cessation of feeding. Sixteen of these genes encode proteins that could form a defective prophage (called Afp for antifeeding prophage $)^{42}$. Expression of the afp genes in E. coli allows the synthesis of particles that resemble phage tail-like bacteriocins ${ }^{43}$. These particles might function as a delivery device for the putative toxins (or effectors) that are encoded by the last two genes. Interestingly, several copies of these prophagelike loci are found in the genome of Photorhabdus luminescens and are named PVC (Photorhabdus virulence cassettes $)^{44}$. It has been proposed that Serratia persistence is ensured by a low toxic activity of Afp. This is supported by the fact that overexpression of the afp locus leads to some degree of lethality. The second locus that is involved in amber disease is responsible for the gut-clearance phenomenon ${ }^{40}$ and encodes proteins that are related to the insecticidal toxins (Tc-toxins) that are found in P. luminescens and other bacteria.

Gut physiology perturbations and pathogenicity. Afp is not the only persistence factor that might perturb (directly or indirectly) gut physiology through a toxic effect on epithelial cells ${ }^{41}$. When the Erwinia persistence factor evf is overexpressed in Erwinia strains, infected larvae stop feeding (suggesting a food-uptake blockage), bacteria proliferate and a strong lethality is observed ${ }^{36,37}$. A third example of toxicity towards the insect gut is observed with P. entomophila, a bacterium that can infect and kill $D$. melanogaster larvae and adults after ingestion $^{31}$. D. melanogaster infection by P. entomophila is also characterized by a cessation of feeding. Electron microscopy observations showed that infection with P. entomophila causes a loss of larval midgut integrity ${ }^{31}$. 


\section{Box $1 \mid$ A case of bacterial persistence outside the gut, after ingestion}

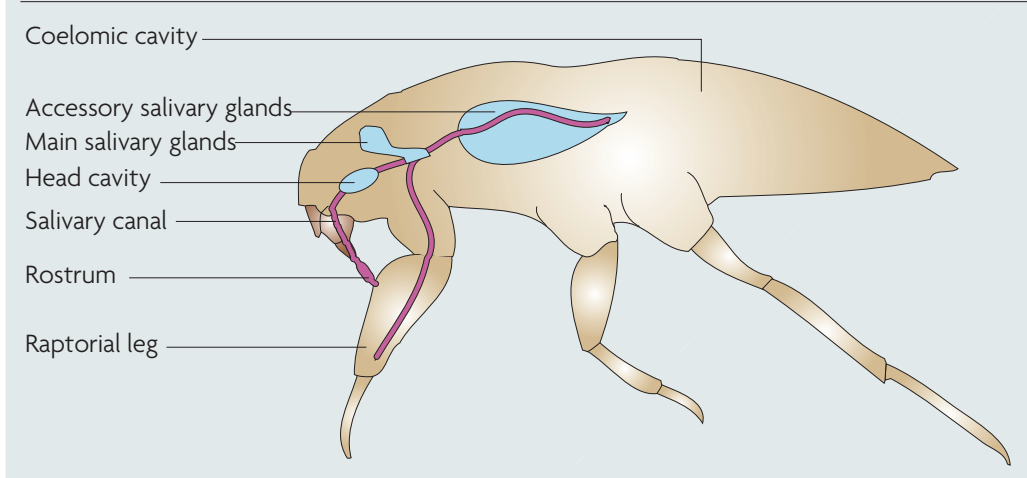

Bacteria can move out of the insect digestive tract to colonize other organs (see the figure). The figure shows a schematic representation of the median sagittal section of the water bug Naucoris cimicoides. Mycobacterium ulcerans, the causative agent of Buruli ulcer, colonizes the salivary glands of N. cimicoides. Between $5 \%$ and $10 \%$ of $N$. cimicoides that are captured in endemic areas are infected with $M$. ulcerans ${ }^{88}$. Immediately after ingestion, $M$. ulcerans translocates from the head capsule to the coelomic cavity. In this cavity it is phagocytosed by plasmatocytes that serve as shuttle cells and deliver M. ulcerans to the salivary glands, where M. ulcerans proliferates without damaging insect tissues ${ }^{89,90}$. Interestingly, the dermonecrotic toxin mycolactone, which is the only virulence factor that has been characterized for M. ulcerans, is required for plasmatocyte evasion and establishment of bacteria in the salivary glands ${ }^{89}$.M. ulcerans can proliferate to colonize the salivary canals and the inside cavity of the raptorial legs, where it synthesizes an extracellular matrix that promotes formation of a biofilm-like structure ${ }^{89}$. This matrix is important for bacterial translocation, and its presence enhances colonization of insect vectors and mammalian hosts ${ }^{91}$. It has been proposed that $N$. cimicoides can also serve as a vector that contributes to the dissemination of M. ulcerans ${ }^{90}$. Figure modified with permission from REF. 89 ๑ (2005) Blackwell Publishing.

Comparative transcriptome analysis of $D$. melanogaster larvae orally infected by P. entomophila or E. c. carotovora 15 revealed that the expression of 205 genes is altered during a lethal infection compared with a non-lethal infection. Most of these genes are important in gut physiology, which indicates that $P$. entomophila modifies the gut epithelium during the infectious process. One example of this is the activation of insect genes that encode cytoskeleton components that are regulated by the JNK pathway ${ }^{31}$.

The observations made with E. c. carotovora 15 (REF. 37) suggest that peristaltic movements of the gut might play an important role in the elimination of bacteria and that entomopathogens have developed strategies to abrogate peristalsis.

\section{Immune defences in the gut}

Bacteria that can persist after ingestion are faced with the insect immune response (BOX 2) and can often counteract host defences. The first level of immune response occurs at the site of the infection, in the insect gut (FIG. 2). AMP production in the gut epithelium can be triggered by E. c. carotovora 15 (REF. 36), P. entomophila ${ }^{31}$ and S. marcescens $^{33}$. This local response is mediated by the nuclear factor (NF) $-\kappa B$ signalling pathway called $\operatorname{Imd}^{18,45}$, through the recognition of Gram-negative peptidoglycan by the peptidoglycan recognition proteins (PGRPs), such as PGRP-LC ${ }^{46}$ (BOX 2).

Why commensal bacteria do not generate a state of permanent immune activation in tissues such as the gut is unclear. A central role in gut tolerance to bacteria has been attributed to amidase PGRPs (PGRP-LB and PGRP-SC) as they abrogate the immunostimulatory activity of peptidoglycan fragments that are released by commensals $^{46,47}$. It is also interesting to note the existence of specialization in the gut epithelium as only parts of the epithelium are immunoreactive, whereas bacteria are present throughout the midgut after infection ${ }^{18,30,31}$.

It has been suggested that local AMP production in the gut is a second line of defence, after ROS production, to fight oral ingestion of bacteria. Indeed, in contrast to wild-type D. melanogaster, imd-deficient flies are highly susceptible to oral ingestion of ROS-resistant E. coli. This lethality disappears when a functional imd pathway is re-introduced into the intestinal epithelium, or when only the AMP cecropin is expressed in the gut ${ }^{48}$.

The local production of AMP also has an important role in fighting oral infection by pathogenic bacteria. $D$. melanogaster is protected against oral infection by $P$. entomophila by activating the local AMP production in the gut before infection ${ }^{49}$. Furthermore, D. melanogaster that has a functional Imd pathway only in the gut was as resistant as wild-type flies to infection by $P$. entomophila or other persisting microorganisms, demonstrating that the local gut response is of prime importance in the fight against infection by the oral route.

Bacteria can fight this local immune response. For instance P. entomophila can persist in wild-type D. melanogaster larvae as well as in larvae that have been deprived of an immune response ${ }^{31}$, suggesting that this bacterium can evade the D. melanogaster immune response. P. entomophila might protect itself from immune effectors such as AMP, or it might degrade these effectors. Among the various putative virulence factors that are encoded in the P. entomophila genome ${ }^{50}$, the secreted zinc metalloprotease AprA has a pivotal role in the defence of $P$. entomophila against the host gut epithelial immune response ${ }^{49}$. Not only is an aprA mutant slightly less virulent, it is also less able to persist in D. melanogaster than wild-type P. entomophila, and is more sensitive to Imd-mediated defences. AprA also provides specific protection against the diptericin AMP, demonstrating in vivo the role of a secreted protease to protect bacteria against insect $\mathrm{AMPs}^{49}$.

Systemic immune defences. AMPs are sometimes produced by the fat body cells (the fat body could be considered as an analogue of the mammalian liver) and secreted into the insect haemolymph. This happens when microorganisms are directly injected into the body cavity, but persisting bacteria in the gut can also induce AMP production. Bacterial persistence in the gut is probably the first step that is required for the activation of this systemic AMP response after ingestion.

To analyse the responses that are induced by E. c. carotovora 15 and P. entomophila oral infection of $D$. melanogaster larvae, a genomic approach was used. Microarrays were used to analyse transcriptomes of $D$. melanogaster larvae that were infected either by ingestion (oral infection) of E. c. carotovora 15 or 

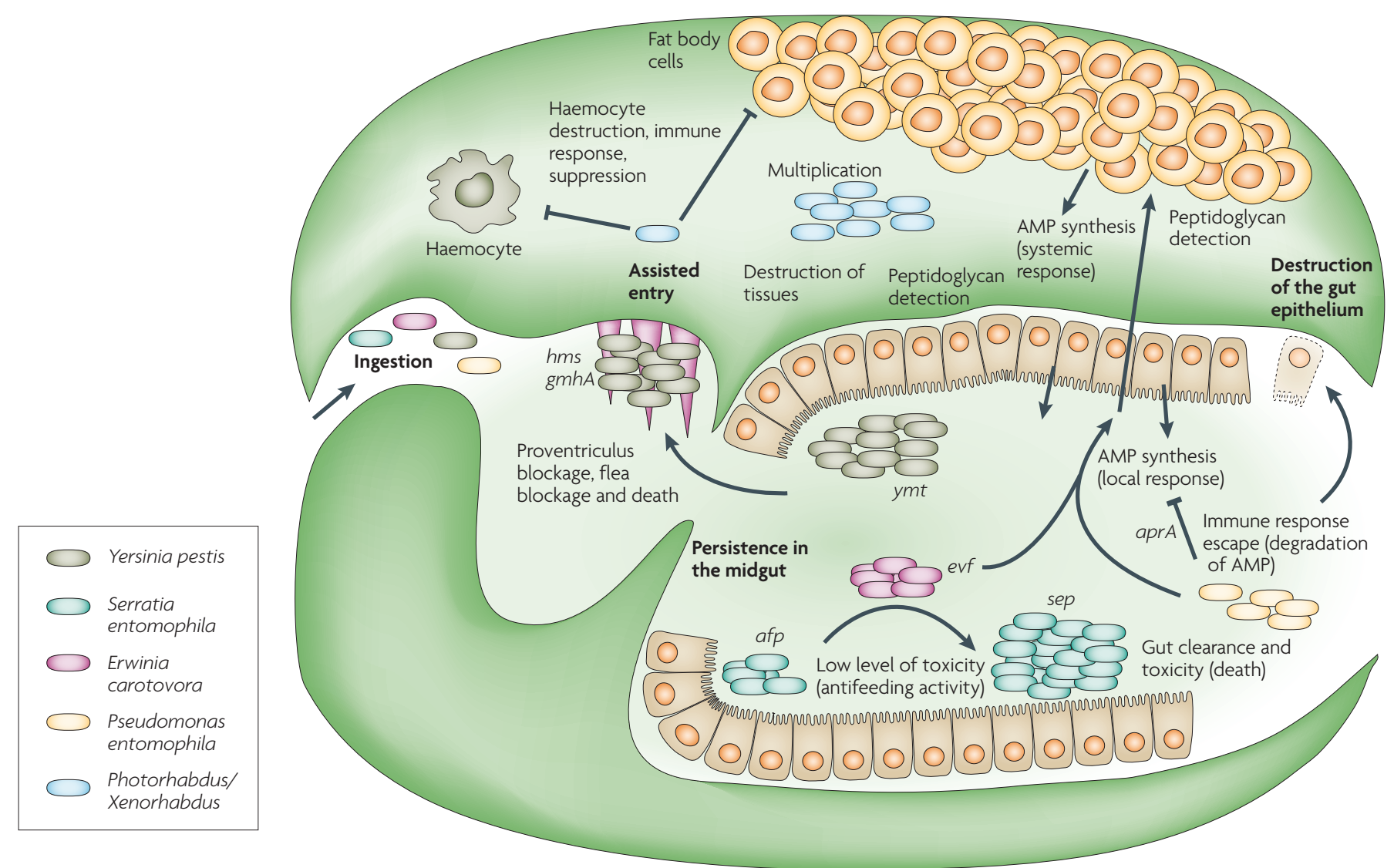

Figure 3 | Examples of bacterial infections in insects. The different bacteria discussed in the text are indicated by different colours, and the names of the genes involved in different steps of infection are indicated. After ingestion or assisted entry, bacteria use different strategies to persist in the insect host. Yersinia pestis, Serratia entomophila and Erwinia carotovora rely on a limited number of genes to persist in the gut. Photorhabdus and Xenorhabdus sp. suppress the immune response and kill phagocytic cells. Persistence of Erwinia carotovora subsp. carotovora 15 or Pseudomonas entomophila in the gut triggers antimicrobial peptide (AMP) production at both local and systemic levels. It leads to E. c. carotovora 15 elimination, whereas P. entomophila relies on the AprA protease to neutralize AMPs. Y. pestis colonizes the flea proventriculus through the formation of a biofilm-like structure. Upon suppression of the immune response, Photorhabdus and Xenorhabdus sp. proliferate in the insect body. Persisting bacteria provoke host damage. P. entomophila infection is characterized by destruction of the Drosophila midgut epithelium. Proventriculus colonization by Y. pestis leads to 'blockage', which prevents food uptake and reduces the flea lifespan. Proliferation of Photorhabdus and Xenorhabdus sp. ensures degradation of insect tissues, which provides nutrients to the nematode vectors.

P. entomophila, or by direct injection of microorganisms into the body cavity (septic injury). Genes that were modulated during infection by the different routes could thus be identified ${ }^{31}$. Oral infection by E. c. carotovora 15 or P. entomophila induced 72 of the 99 genes that were upregulated after direct injection, indicating that naturally infectious Gram-negative bacteria can induce most of the larval immune-regulated genes. These include AMP genes, genes that are involved in recognition and phagocytosis, genes that encode small immune-regulated peptides and unknown genes. Furthermore, oral infection by E. c. carotovora 15 or P. entomophila affects the expression of 92 genes whose expression is not modulated by septic injury. These genes mainly encode proteases, constituents of the peritrophic membrane, and gene products that are involved in metabolism, and might constitute the host response to bacterial persistence in the gut. These genes are promising post-genomic targets for a detailed analysis of the gut-infection process.
The activation of AMP production by the fat body also relies on peptidoglycan recognition by $\mathrm{PGRPs}^{51,52}$ (BOX 2). It is interesting to note that high titres of ingested Gram-negative bacteria, such as E. coli or E. c. carotovora 15 evf mutants, do not induce systemic AMP production, even though they are present in large numbers in the gut several hours after ingestion $^{36,37}$. Once again, this may be due to the presence of another type of PGRP with amidase activity that establishes a tolerance threshold level of bacteria in the gut by reducing the amount of active peptidoglycan fragments ${ }^{46,47}$. The absence of systemic AMP production despite a high level of non-infectious bacteria at early time points after ingestion indicates that the triggering of this systemic response by infectious bacteria such as E. c. carotovora 15 or P. entomophila either requires bacterial persistence and de novo synthesized peptidoglycan compounds, or depends on the detection of peptidoglycan molecules in a specific
The ability to colonize a host and induce the host immune response. 


\section{Box $2 \mid$ Insect immune response}

To fight infection, insects rely on multiple innate defence mechanisms, many of which are shared with higher organisms ${ }^{92}$. These immune functions have mainly been characterized in Drosophila melanogaster, which serves as a paradigm for insect immunity. The figure shows a diagram of systemic immune response in Drosophila. Pathogen recognition triggers three major defence mechanisms at the systemic level: production of antimicrobial peptides (AMPs) and other immune effectors by fat body cells, activation of the cellular response, and the melanization reaction. Peptidoglycan detection in the haemolymph leads to activation of the Imd or the Toll pathways. Haemocytes are responsible for bacterial phagocytosis. Melanotic nodules are formed after activation of the melanization cascade. Production of AMPs, cellular response and melanization are the main defence mechanisms.

Recognition of invading bacteria relies on specific molecules that are named peptidoglycan recognition proteins (PGRPs). All PGRPs contain at least one domain that is similar to the prokaryotic peptidoglycan-lytic type 2 amidase, but only some PGRPs have amidase enzymatic activity; other PGRPs have a major role in microbial recognition.

In D. melanogaster, the synthesis of immune effectors by the fat body is under the control of the Toll and Imd signalling pathways ${ }^{93}$. Each of these pathways activates specific nuclear factor (NF)- $\mathrm{KB}$ transactivators, which in turn switch on specific programmes of transcription. The ability of $D$. melanogaster to discriminate between Gram-negative and Gram-positive bacteria is based on the recognition of specific forms of peptidoglycan ${ }^{51}$ by different PGRPs ${ }^{52}$. The Toll pathway is mainly activated by Gram-positive bacteria and fungi, and induces the synthesis of several peptides, including the antifungal peptide drosomycin. Recognition of lysine-type peptidoglycans, which are found in many Gram-positive bacteria, is mediated by PGRP-SA and PGRP-SD. The Imd pathway is mainly activated by Gram-negative bacteria through the recognition of the diaminopimelic acid (DAP)-type peptidoglycan by specific PGRPs (such as PGRP-LC). Activation of the Imd pathway induces the expression of different AMPs, such as diptericin, that are active against a range of bacteria and fungi. Moreover, Imd pathway activity in larvae can be modulated by nitric oxide ${ }^{94}$, and this input is mediated by calcineurin, a Ca $^{2+}$-dependent phosphatase ${ }^{95}$.

In addition to the systemic response, insects rely on a local immune response that allows the synthesis of AMPs and reactive oxygen species in surface epithelia, such as gut or trachea, in a tissue-specific manner ${ }^{18,45,96}$. It has been proposed that the systemic immune response that is induced during gut infection is mediated by the translocation of peptidoglycan fragments from the gut lumen to the haemolymph ${ }^{46,47}$.

Another major aspect of insect immunity is the cellular immune response. Different types of free and sessile blood cells, named haemocytes, are activated in response to infection, but our understanding of the mechanisms and consequences of this activation is still fragmentary. Mobile plasmatocytes in the haemocoel are responsible for phagocytosis, which is important to fight bacterial invasion ${ }^{97}$.

The melanization process is a humoral response that relies on a proteolysis cascade that results in the activation of the prophenoloxidase. Specialized insect haemocytes can promote melanization, haemocyte aggregation and nodulation, encapsulation or opsonization. Recognition of microbial compounds, such as $\beta$-1,3-glucans, lipopolysaccharides and peptidoglycan, ensures that the humoral response is effective ${ }^{88,99}$. Once activated, phenoloxidase catalyses the formation of melanotic nodules that limit the spread of infecting microorganisms or damaged tissues. Figure modified with permission from REF. 93 @ (2007) Annual Reviews.

compartment of the gut. Therefore, the induction of systemic AMP production seems to be a direct consequence of bacterial persistence in the gut.

\section{Direct injection as a route of infection}

In nature, ingestion of microorganisms is probably the main route of insect infection. However bacteria can sometimes access the haemocoel directly, either through an accidental breaching of the cuticle, or by assisted transport via an entomophagous host, such as a nematode. Breaching the cuticle can enable opportunistic bacteria to colonize the insect. This type of infection is readily mimicked in the laboratory by direct injection of bacteria into the body cavity and has been exploited to decipher the recognition and signalling molecules that are involved in the immune response, and to identify bacterial virulence factors ${ }^{6}$.

Assisted transport by entomophagous nematodes has been documented for two bacterial species, P. luminescens and Xenorhabdus nematophila ${ }^{53}$. These 


\section{Box $3 \mid$ Heritable microorganisms}

Females of many insect species interact with various different bacteria that are vertically transmitted to progeny ${ }^{9}$. These interactions are complex and the outcomes range from mutualistic to parasitic phenotypes, depending on the host and the bacteria involved. On the one hand, in mutualistic interactions the host relies on the symbiotic microorganism to supply nutrients that are required for viability and fertility. Examples of primary symbionts that colonize a specific organ include Buchnera species in aphids (Homoptera) or Wigglesworthia glossinidia in Tsetse flies. On the other hand, interactions can lead to different forms of pathogenic 'reproductive parasitism' ${ }^{100}$, including parthenogenesis, feminization, male killing or cytoplasmic incompatibility. Two different bacterial genera have been documented in many cases of heritable parasitism: Wolbachia and Spiroplasma species.

Wolbachia pipientis is an obligate endocellular symbiont with an extremely broad host range ${ }^{101}$. Wolbachia mainly inhabits the reproductive tissues of hosts. However, it can also be found in various somatic tissues ${ }^{102}$, and its distribution varies between different Wolbachia-host associations. Unlike other persisting bacteria that are described in this Review, Wolbachia infection often fails to induce or suppress the host immune response ${ }^{103}$. The absence of effects on host immunity likely results from the stealth of Wolbachia cells inside the host cells. In some cases, Wolbachia strains are pathogenic ${ }^{104}$ and infection leads to rupture of host cells and release of bacteria; thus, induction of the expression of genes that encode the host antimicrobial peptide cecropin $\mathrm{C}$ and lysozyme ${ }^{101}$ might result from the detection of bacterial immune elicitors.

The mollicute genus Spiroplasma lacks a cell wall, is vertically transmitted from mother to progeny and kills male embryos - infection is characterized by all-female broods. How Spiroplasma kills male embryos is not known. Although the bacterium is widely distributed in different tissues, it accumulates at high concentrations in haemolymph. The presence of Spiroplasma does not induce expression of any of seven antimicrobial genes in Drosophila ${ }^{55}$. The absence of an immune response does not result from immunosuppression, as the response can be induced by septic injury in Drosophila melanogaster that is already infected by Spiroplasma ${ }^{55}$. The absence of a response upon Spiroplasma infection results from an absence of elicitors; the lack of wall structure, including peptidoglycan, might explain the success of Spiroplasma in colonizing many species of insects.

bacteria colonize the gut of specific nematode hosts (Heterorhabditis and Steinernema, respectively) when they are in the infective soil-dwelling life-cycle stage, named the infective juvenile (IJ) stage. Before the IJ stage, a low number of Photorhabdus and Xenorhabdus cells colonize their respective hosts using different processes $^{54}$; these bacteria reproduce inside the host to produce a mature population of 50-150 colony forming units per IJ. After entering an insect, IJs migrate to the haemolymph, where they release their bacterial symbionts. Both Photorhabdus and Xenorhabdus bacteria evade the immune response, kill the insect and supply the nematode with nutrients from the cadaver to produce several hundred thousand IJs $\mathrm{s}^{53}$.

\section{Counteracting the systemic immune response} Two main strategies are used by pathogens to escape the systemic immune response: they avoid detection because they lack (or hide) immune elicitors on their cell surfaces, or they suppress the immune response. The first strategy is used by a pathogen from the Spiroplasma genus that can infect flies without being detected and also without interfering with the immune response $^{55}$ (BOX 3).

The second strategy is used by the two assisted invaders $P$. luminescens and $X$. nematophila, which can impair both cellular and humoral responses (BOX 2). Several studies have indicated that X. nematophila causes immunosupression at different levels ${ }^{56}$. The cellular response is dampened through the killing of haemocytes within 3 hours of infection, probably by the toxic effects of cytolysin, lipopolysaccharide, toxins and fimbrial subunits ${ }^{56}$. The humoral response can also be suppressed by repressing AMP gene expression through a mechanism that remains to be characterized $^{57}$. In a similar way, Pseudomonas aeruginosa can suppress D. melanogaster defence responses by limiting AMP gene expression when injected into the fly haemolymph ${ }^{58}$, using a mechanism that also remains to be characterized. Additionally, X. nematophila and Photorhabdus temperata can inhibit phospholipase A2 (PLA2) ${ }^{59}$, which catalyses the first step of eicosanoid biosynthesis. Eicosanoids are important for haemocyte nodulation and prophenoloxidase activation ${ }^{60}$.

The infection of Manduca sexta by P. luminescens results in the transcriptional activation of several immune-regulated genes. Although P. luminescens can overcome this response, if it is absent the bacteria proliferate more rapidly and the insect dies sooner ${ }^{61}$. P. luminescens also uses a type III secretion system to inhibit phagocytosis ${ }^{62}$. The melanization of pathogens and damaged tissues (BOX 2) is a further insect innate immune defence. P. luminescens produces an antibiotic molecule, (E)-1-3-dihydroxy-2-(isopropyl)-5(2-phenyethylenyl) benzene (known as ST), that inhibits phenoloxidase ${ }^{63}$, the main melanization enzyme. P. luminescens mutants that cannot synthesize ST are reduced in virulence, replicate more slowly in the host and cause the insect to produce more melanotic nodules than wild-type bacteria.

\section{Virulence factors and toxins}

Despite the characterization of multiple virulence factors, how pathogens kill insects is not known. Disease either results from bacterial proliferation or from damage caused by a toxic factor (or factors). Analysis of pathogenesis in different systems has indicated a crucial role for factors that enable persistence (such as Evf, Afp, Ymt and Hms) and factors that counteract the immune response (such as AprA, ST, cytolysins and haemocyte killing factors). Plus, different toxic factors can have a combinatorial action in pathogenesis. 


\begin{tabular}{|c|c|c|}
\hline Toxin & Organisms identified in & Other producer organisms \\
\hline $\begin{array}{l}\text { Insecticidal toxin } \\
\text { complexes (Tc-toxin) }\end{array}$ & $\begin{array}{l}\text { Photorhabdus spp. } .^{116} \\
\text { Xenorhabdus sp. }{ }^{117}\end{array}$ & $\begin{array}{l}\text { Serratia entomophila }{ }^{40}, \\
\text { Yersinia spp., } \\
\text { Pseudomonas spp., } \\
\text { Fibrobacter succinogenes, } \\
\text { Paenibacillus nematophila11 }\end{array}$ \\
\hline Cyt and Cry toxins & Bacillus thuringiensis ${ }^{110}$ & Dickeya dadantii ${ }^{78}$ \\
\hline Binary toxin (BinAB) & Bacillus sphaericus ${ }^{119}$ & \\
\hline $\begin{array}{l}\text { Makes caterpillar } \\
\text { floppy (Mcf) }\end{array}$ & Photorhabdus spp. ${ }^{120}$ & \\
\hline Binary toxins (PirAB) & Photorhabdus spp..$^{71}$ & \\
\hline
\end{tabular}

Although virulence factors are often predicted to impair host defences and harm host tissues, these factors can be pleiotropic, as they are also involved in biocontrol ${ }^{64}$.

In contrast to vertebrate and plant pathogens $\mathrm{s}^{65}$, bacteria that infect insects by ingestion do not seem to rely on type III secretion systems during pathogenesis. This might be due to the architecture of the insect gut, in which the peritrophic membrane separates the food bolus from the epithelial cells, such that direct cell-bacteria contact does not occur in most interactions.

Specific toxins that are active against insects have been identified (TABLE 2). The best studied of these are the Cry and Cyt toxins of B. thuringiensis, which are used in biocontrol (BOX 4). Other insecticidal toxins have also been found in P. luminescens and $X$. nematophila. They are likely to play an important role in the pathogenic process that leads to insect death upon infection by these bacteria. However, their mode of action is not always known, and some genes that encode similar toxins have been identified in bacteria that are not bona fide entomopathogens. Therefore, the exact role of these toxins in the lifestyle of many bacteria is still unknown.

Degradative enzymes, including lipases, proteases and haemolysins, might also contribute to the virulence of entomopathogens. Proteases, especially metalloproteases, contribute to virulence in pathogenic bacteria including $P$. aeruginosa, $S$. marcescens and $B$. thuringiensis ${ }^{66-68}$. In addition to degrading
AMPs, proteases might be involved in the destruction of cells and tissues to facilitate colonization of the insect body ${ }^{69}$. During symbiotic associations between bacterial entomopathogens and nematodes, proteases might also provide nutrients to their nematode hosts ${ }^{70}$, which multiply in the dead insect body.

In addition to protein factors, several entomopathogens produce toxic secondary metabolites ${ }^{50,71}$ that might either harm the host or out-compete other microorganisms ${ }^{64}$.

Global regulators play an important role in virulence towards insects: the GacS/GacA two-component system controls the $P$. entomophila infectious proc$\mathrm{ess}^{50}$, PhoP/PhoQ is the master regulator of virulence in P. luminescens ${ }^{72}$, Lrp regulates both mutualism and pathogenicity in Xenorhabus ${ }^{73}$ and PlcR activates the transcription of genes required for virulence in B. thuringiensis ${ }^{74,75}$. Another striking example is found in E. c. carotovora 15, where the evf gene is under the control of Hor, a regulator of genes that are involved in plant pathogenesis ${ }^{36}$. This trend reveals the benefits that bacteria might gain from integrating potential virulence factors under the control of global regulators that activate gene expression when the conditions are right.

\section{Evolving into an entomopathogen}

Many bacterial entomopathogens belong to bacterial genera that are not normally associated with insects, which suggests that the ability to interact with insects depends on the acquisition of a limited number of determinants. In simplistic terms, to become an entomopathogen, the bacteria must first occupy the same ecological niche as the insect; second, it must acquire the ability to persist in insects, for example through the acquisition of evf or $y m t$; third, bacteria need to evade the host response, by degrading antibacterial effectors or by becoming insensitive to their effects; fourth, persistent infection should enable colonization of insect tissues and/or impair host physiology by the production of toxins. The rapid evolutionary transition of $Y$. pestis from a mammalian enteric pathogen into a blood-borne pathogen of insects suggests that a few events enabled the evolution of this entomopathogen. One important step was the acquisition of two plasmids carrying pla and $y m t$ genes $^{76}$. Similarly, the

\section{Box 4 | Bacillus thuringiensis and other Bacillus spp.}

Bacillus thuringiensis is a Gram-positive, sporulating facultative entomopathogen that is found in various ecological niches such as soil, plant surfaces, dust from stored products and insects. B. thuringiensis spores persist for a long time and can germinate in soil and on plants ${ }^{105}$. Other sporulating bacilli that are similar to $B$. thuringiensis are also entomopathogens (TABLE 1). The insecticidal proteins that are contained in the parasporal crystals are the main factors in determining the host range of $B$. thuringiensis. The mechanism of action of the crystal toxins has been reviewed elsewhere ${ }^{106-109}$. Because of the prime role of toxins in the pathogenesis of $B$. thuringiensis ${ }^{110}$, other virulence factors have not been well studied. The role of the spores fed to larvae seems to be highly variable and depend on the type, combination and concentration of Cry toxins, the type and density of bacteria, the insect species and the presence of microorganisms in the gut ${ }^{111}$. Several models have been proposed for the pathogenic effect of $B$. thuringiensis: it has been proposed that disruption of the gut epithelium results in a prolonged cessation of feeding and eventual death by starvation. Alternatively, gut cell lysis might provide spores or germinated cells with access to the haemocoel, leading to septicaemia. It was recently shown that B. thuringiensis does not kill larvae of the gypsy moth in the absence of indigenous midgut bacteria, which implies that the resident enteric bacteria are responsible for the septicaemia that is associated with $B$. thuringiensis toxicity in gypsy moth ${ }^{112}$. 
ability to colonize and persist in insect species might have resulted from horizontal gene transfer (HGT) of plasmid-borne persistence genes in S. entomophila (afp-encoding genes) and in M. ulcerans (mycolactone biosynthetic genes). A role for HGT in the evolution of entomopathogens is also revealed by the distribution of genes that encode similar toxins in unrelated genera $^{50,77,78}$, which suggests that the insect gut constitutes an environment that is favourable for gene transfer ${ }^{79}$.

\section{Conclusion and perspectives}

The evolutionary success of insects indicates that they have developed strategies to fight bacterial infections. In several cases, constitutive expression of the Imd pathway of AMP genes results in host protection $^{49,50,80,81}$, which reveals the importance of the race between the establishment of resistant bacterial populations and the activation of the immune response. Furthermore, it demonstrates that the host immune response can be effective against invaders.

Comparison of immune gene repertoires among sequenced insect genomes revealed the conservation of pathways and effectors, at least in Diptera, Hymenoptera and Coleoptera ${ }^{82-84}$. The lepidopteran insect Manduca sexta encodes immune effectors that are similar to those of other insects ${ }^{85}$. Furthermore, insect immune pathways share an overall architecture and specific orthologous components with the innate immune system of vertebrates. We might therefore anticipate that strategies used to fight bacterial infections will be similar in many insect species, at least in holometabolous species that develop through a pupal stage. Using holometabolous insect species, molecular mechanisms of host-pathogen interactions have been obtained. However, the antibacterial strategies and immune responses that have been developed by hemimetabolous insects remain uncharacterized.

For many years, insects have been considered as vectors of human, animal or plant pathogens. It is becoming evident that persistence of bacteria in insect hosts involves crosstalk that is similar to the crosstalk that is required for bacterial persistence in other metazoan hosts. The acquisition of determinants that counteract insect host defences by bacteria might change the host range of pathogens.

The potential offered by models that are amenable to genetic and genomic approaches is only now starting to emerge. Future studies using host and pathogen models should enable a detailed characterization of the main steps of an infectious process; that is, persistence in the host, detection of the invading bacteria, signalling to specialized tissues, evasion of the immune response and pathogenic effects. Another promising development provided by such models concerns the effect of intestinal flora on health and disease. Commensal microbiota in D. melanogaster protect the host from potential ingested pathogens, and modulation of host innate immune homeostasis might modify the commensal community ${ }^{86}$.

Studies of insect-pathogen interactions suffer from a lack of knowledge of insect pathology $y^{87}$. In most cases, the physiological process(es) whose alteration is responsible for death is not known. Markers used in human pathologies comprise fever, blood analysis, urine analysis, faecal analysis and other factors. The identification of useful markers for pathogenesis together with the genetic, genomic and biochemical tools that can be used to study insects will revolutionize the understanding of bacterial infection and pathogenesis of insects.
1. Boucias, D. G. \& Pendland, J. C. Principles of Insect Pathology (Kluwer Academic Publishers, Dordrecht, 1998).

2. Federici, B. A., Park, H. W., Bideshi, D. K., Wirth, M. C \& Johnson, J. J. Recombinant bacteria for mosquito control. J. Exp. Biol. 206, 3877-3885 (2003).

3. Aballay, A. \& Ausubel, F. M. Caenorhabditis elegans as a host for the study of host-pathogen interactions. Curr. Opin. Microbiol. 5, 97-101 (2002).

4. Cosson, P. et al. Pseudomonas aeruginosa virulence analyzed in a Dictyostelium discoideum host system. J. Bacteriol. 184, 3027-3033 (2002).

5. Rahme, L. G. et al. Use of model plant hosts to identify Pseudomonas aeruginosa virulence factors. Proc. Natl Acad. Sci. USA 94, 13245-13250 (1997).

6. Vodovar, N., Acosta, C., Lemaitre, B. \& Boccard, F. Drosophila: a polyvalent model to decipher hostpathogen interactions. Trends Microbiol. 12, 235-242 (2004).

7. Clarkson, J. M. \& Charnley, A. K. New insights into the mechanisms of fungal pathogenesis in insects. Trends Microbiol. 4, 197-203 (1996).

8. Baumann, P. \& Moran, N. A. Non-cultivable microorganisms from symbiotic associations of insects and other hosts. Antonie Van Leeuwenhoek 72, 39-48 (1997)

9. Gil, R., Latorre, A. \& Moya, A. Bacterial endosymbionts of insects: insights from comparative genomics. Environ. Microbiol 6, 1109-1122 (2004).

10. Bulla, L. A., R. A., R. \& St. Julian, G. Bacteria as insect pathogens. Annu. Rev. Microbiol. 29, 163-190 (1975).

11. Lysenko, O. Non-sporeforming bacteria pathogenic to insects: incidence and mechanisms. Annu. Rev. Microbiol. 39, 673-695 (1985).
12. Kobayashi, M. et al. Houseflies: not simple mechanical vectors of enterohemorrhagic Escherichia coli 0157 H7. Am. J. Trop. Med. Hyg. 61, 625-629 (1999).

13. Douglas, A. E. \& Beard, C. B. in Biology of the Insect Midgut (eds Lehane, M. J. \& Billingsley, P. F.) (Chapman \& Hall, London, 1996).

14. Kaslow, D. C. \& Welburn, S. in Biology of the Insect Midgut (eds Lehane, M. J. \& Billingsley, P. F.) (Chapman \& Hall, London, 1996).

15. Pai, H. H., Chen, W. C. \& Peng, C. F. Cockroaches as potential vectors of nosocomial infections. Infect. Control Hosp. Epidemiol. 25, 979-984 (2004).

16. Gage, K. L. \& Kosoy, M. Y. Natural history of plague: perspectives from more than a century of research. Annu. Rev. Entomol. 50, 505-528 (2005).

17. Chapman, R. F. The Insects: Structure and Function (Cambridge University Press, Cambridge, 1998).

18. Tzou, P. et al. Tissue-specific inducible expression of antimicrobial peptide genes in Drosophila surface epithelia. Immunity 13, 737-748 (2000).

19. Hao, Z., Kasumba, I. \& Aksoy, S. Proventriculus (cardia) plays a crucial role in immunity in tsetse fly (Diptera: Glossinidiae). Insect Biochem. Mol. Biol. 33, 1155-1164 (2003).

20. Jarrett, C. O. et al. Transmission of Yersinia pestis from an infectious biofilm in the flea vector. J. Infect. Dis. 190, 783-792 (2004).

21. Ha, E. M., Oh, C. T., Bae, Y. S. \& Lee, W. J. A direct role for dual oxidase in Drosophila gut immunity. Science 310, 847-850 (2005). Shows that dual oxidase is indispensable for gut antimicrobial activities in adult Drosophila.

22. Ha, E. M. et al. An antioxidant system required for host protection against gut infection in Drosophila. Dev. Cell 8, 125-132 (2005).
Shows that homeostasis in redox balance modulates host survival after ingestion of bacteria

23. Hinnebusch, B. J. et al. Role of Yersinia murine toxin in survival of Yersinia pestis in the midgut of the flea vector. Science 296, 733-735 (2002). Identification of the gene that is responsible for gut persistence in fleas.

24. Perry, R. D., Pendrak, M. L. \& Schuetze, P. Identification and cloning of a hemin storage locus involved in the pigmentation phenotype of Yersinia pestis. J. Bacteriol. 172, 5929-5937 (1990).

25. Parsek, M. R. \& Singh, P. K. Bacterial biofilms: an emerging link to disease pathogenesis. Annu. Rev. Microbiol. 57, 677-701 (2003).

26. Hinnebusch, B. J., Perry, R. D. \& Schwan, T. G. Role of the Yersinia pestis hemin storage ( $h m s$ ) locus in the transmission of plague by fleas. Science $\mathbf{2 7 3}$ 367-370 (1996).

Identification of the gene responsible for proventriculus colonization and digestive tract blockage.

27. Darby, C., Ananth, S. L., Tan, L. \& Hinnebusch, B. J. Identification of $g m h A$, a Yersinia pestis gene required for flea blockage, by using a Caenorhabditis elegans biofilm system. Infect. Immun. 73, 7236-7242 (2005).

28. Flyg, C., Kenne, K. \& Boman, H. G. Insect pathogenic properties of Serratia marcescens: phage-resistant mutants with a decreased resistance to Cecropia immunity and a decreased virulence to Drosophila. J. Gen. Microbiol.120, 173-181 (1980).

29. Chugani, S. A. et al. QscR, a modulator of quorumsensing signal synthesis and virulence in Pseudomonas aeruginosa. Proc. Natl Acad. Sci. USA 98, 2752-2757 (2001). 
30. Basset, A. et al. The phytopathogenic bacteria Erwinia carotovora infects Drosophila and activates an immune response. Proc. Natl Acad. Sci. USA 97, 3376-3381 (2000).

First report of immune-response activation after ingestion of bacteria by Drosophila larvae.

31. Vodovar, N. et al. Drosophila host defense after ora infection by an entomopathogenic Pseudomonas species. Proc. Natl Acad. Sci. USA 102,

11414-11419 (2005).

Characterization of $P$. entomophila pathogenicity in Drosophila.

32. Blow, N. S. et al. Vibrio cholerae infection of Drosophila melanogaster mimics the human disease cholera. PLoS Pathog. 1, e8 (2005)

33. Nehme, N. T. et al. A model of bacterial intestinal infections in Drosophila melanogaster. PLoS Pathog. 3, e173 (2007).

Characterization of $S$. marcescens pathogenicity in Drosophila.

34. Kloepper, J. W., Brewer, J. W. \& Harisson, M. D. Insect transmission of Erwinia carotovora var. carotovora and Erwinia carotovora var. atroseptica to potato plants in the field. Am. Potato. J. 58, 165-175 (1981).

35. Molina, J. J., Harisson, M. D. \& Brewer, J. W. Transmission of Erwinia carotovora var. atroseptica by Drosophila melanogaster meig. I. Acquisition and transmission of the bacterium. Am. Potato J. $\mathbf{5 4}$ 245-250 (1974).

36. Basset, A., Tzou, P., Lemaitre, B. \& Boccard, F. A single gene that promotes interaction of a phytopathogenic bacterium with its insect vector, Drosophila melanogaster. EMBO Rep. 4, 205-209 (2003). Identification of the gene that allows bacterial persistence in the Drosophila larval gut.

37. Acosta Muniz, C., Jaillard, D., Lemaitre, B. \& Boccard, F. Erwinia carotovora Evf antagonizes the elimination of bacteria in the gut of Drosophila larvae. Cell. Microbiol. 9, 106-119 (2007).

38. Jackson, T. A., Boucias, D. G. \& Thaler, J. O Pathobiology of amber disease, caused by Serratia spp., in the New Zealand grass grub, Costelytra zealandica. J. Invertebr. Pathol. 78, 232-243 (2001).

39. Hurst, M. R. \& Jackson, T. A. Use of the green fluorescent protein to monitor the fate of Serratia entomophila causing amber disease in the New Zealand grass grub, Costelytra zealandica. J. Microbiol. Methods 50, 1-8 (2002).

40. Hurst, M. R., Glare, T. R., Jackson, T. A. \& Ronson, C. W. Plasmid-located pathogenicity determinants of Serratia entomophila, the causal agent of amber disease of grass grub, show similarity to the insecticidal toxins of Photorhabdus luminescens. J. Bacteriol. 182, 5127-5138 (2000). Identification of determinants responsible for Amber disease.

41. Grkovic, S., Glare, T. R., Jackson, T. A. \& Corbett, G. E. Genes essential for amber disease in grass grubs are located on the large plasmid found in Serratia entomophila and Serratia proteamaculans. Appl. Environ. Microbiol. 61, 2218-2223 (1995).

42. Hurst, M. R., Glare, T. R. \& Jackson, T. A. Cloning Serratia entomophila antifeeding genes - a putative defective prophage active against the grass grub Costelytra zealandica. J. Bacteriol. 186, 5116-5128 (2004).

43. Hurst, M. R., Beard, S. S., Jackson, T. A. \& Jones, S. M. Isolation and characterization of the Serratia entomophila antifeeding prophage. FEMS Microbiol. Lett. 270, 42-48 (2007)

44. ffrench-Constant, R. H., Dowling, A. \& Waterfield, N. R. Insecticidal toxins from Photorhabdus bacteria and their potential use in agriculture. Toxicon 49, 436-451 (2007)

45. Onfelt Tingvall, T., Roos, E. \& Engstrom, Y. The imd gene is required for local Cecropin expression in Drosophila barrier epithelia. EMBO Rep. 2, 239-243 (2001).

46. Zaidman-Remy, A. et al. The Drosophila amidase PGRP-LB modulates the immune response to bacterial infection. Immunity 24, 463-473 (2006).

47. Bischoff, V. et al. Downregulation of the Drosophila immune response by peptidoglycan-recognition proteins SC1 and SC2. PLoS Pathog. 2, e14 (2006).

48. Ryu, J. H. et al. An essential complementary role of NF-кB pathway to microbicidal oxidants in Drosophila gut immunity. EMBO J. 25, 3693-3701 (2006). Shows that intestinal NF-кB- and AMP-dependent immunity is crucial to host survival against ROSresistant bacteria.
49. Liehl, P., Blight, M., Vodovar, N., Boccard, F. $\delta$ Lemaitre, B. Prevalence of local immune response against oral infection in a Drosophila/Pseudomonas infection model. PLoS Pathog. 2, e56 (2006). Shows the importance of the bacterial metalloprotease AprA to counteract AMPs.

50. Vodovar, N. et al. Complete genome sequence of the entomopathogenic and metabolically versatile soil bacterium Pseudomonas entomophila. Nature Biotechnol. 24, 673-679 (2006).

51. Leulier, F. et al. The Drosophila immune system detects bacteria through specific peptidoglycan recognition. Nature Immunol. 4, 478-484 (2003)

52. Royet, J. \& Dziarski, R. Peptidoglycan recognition proteins: pleiotropic sensors and effectors of antimicrobial defences. Nature Rev. Microbiol. 5, 264-277 (2007)

53. Forst, S., Dowds, B., Boemare, N. \& Stackebrandt, E. Xenorhabdus and Photorhabdus spp.: bugs that kill bugs. Annu. Rev. Microbiol. 51, 47-72 (1997).

54 Goodrich-Blair, H. \& Clarke, D. J. Mutualism and pathogenesis in Xenorhabdus and Photorhabdus: two roads to the same destination. Mol. Microbiol. 64 260-268 (2007).

55. Hurst, G. D., Anbutsu, H., Kutsukake, M. \& Fukatsu, T. Hidden from the host: Spiroplasma bacteria infecting Drosophila do not cause an immune response, but are suppressed by ectopic immune activation. Insect Mol. Biol. 12, 93-97 (2003).

Host colonization by bacteria that avoid detection by the insect defences.

56. Herbert, E. E. \& Goodrich-Blair, H. Friend and foe: the two faces of Xenorhabdus nematophila. Nature Rev. Microbiol. 5, 634-646 (2007).

57. Ji, D. \& Kim, Y. An entomopathogenic bacterium, Xenorhabdus nematophila, inhibits the expression of an antibacterial peptide, cecropin, of the beet armyworm, Spodoptera exigua. J. Insect Physiol. 50 489-496 (2004)

58. Apidianakis, Y. et al. Profiling early infection responses: Pseudomonas aeruginosa eludes host defenses by suppressing antimicrobial peptide gene expression. Proc. Natl Acad. Sci. USA 102, 2573-2578 (2005)

59. Park, Y., Kim, Y., Putnam, S. M. \& Stanley, D. W. The bacterium Xenorhabdus nematophilus depresses nodulation reactions to infection by inhibiting eicosanoid biosynthesis in tobacco hornworms, Manduca sexta. Arch. Insect Biochem. Physiol. 52, 71-80 (2003).

60. Kim, Y., Ji, D., Cho, S. \& Park, Y. Two groups of entomopathogenic bacteria, Photorhabdus and Xenorhabdus, share an inhibitory action against phospholipase A2 to induce host immunodepression. J. Invertebr. Pathol. 89, 258-264 (2005).

61. Eleftherianos, I., Millichap, P. J., ffrench-Constant, R. H. \& Reynolds, S. E. RNAi suppression of recognition protein mediated immune responses in the tobacco hornworm Manduca sexta causes increased susceptibility to the insect pathogen Photorhabdus. Dev. Comp. Immunol. 30, 1099-1107 (2006).

A small antibiotic molecule that is produced by Photorhabdus spp. acts as inhibitor of phenoloxidase in Manduca sexta.

62. Brugirard-Ricaud, K. et al. Site-specific antiphagocytic function of the Photorhabdus luminescens type III secretion system during insect colonization. Cell. Microbiol. 7, 363-371 (2005).

63. Eleftherianos, I. et al. An antibiotic produced by an insect-pathogenic bacterium suppresses host defenses through phenoloxidase inhibition. Proc. Natl Acad. Sci. USA 104, 2419-2424 (2007)

64. Haas, D. \& Defago, G. Biological control of soil-borne pathogens by fluorescent pseudomonads. Nature Rev. Microbiol. 3, 307-319 (2005).

65. Galan, J. E. \& Collmer, A. Type III secretion machines: bacterial devices for protein delivery into host cells. Science 284, 1322-1328 (1999).

66. Matsumoto, K. Role of bacterial proteases in pseudomonal and serratial keratitis. Biol. Chem. $\mathbf{3 8 5}$, 1007-1016 (2004)

67. Miyoshi, S. \& Shinoda, S. Microbial metalloproteases and pathogenesis. Microbes Infect. 2, 91-98 (2000)

68. Travis, J., Potempa, J. \& Maeda, H. Are bacterial proteinases pathogenic factors? Trends Microbiol. 3 , 405-407 (1995).

69. ffrench-Constant, R. et al. Photorhabdus: towards a functional genomic analysis of a symbiont and pathogen. FEMS Microbiol. Rev. 26, 433-456 (2003).
70. Bowen, D. J. et al. Genetic and biochemical characterization of PrtA, an RTX-like metalloprotease from Photorhabdus. Microbiology 149, 1581-1591 (2003).

71. Duchaud, E. et al. The genome sequence of the entomopathogenic bacterium Photorhabdus luminescens. Nature Biotechnol. 21, 1307-1313 (2003).

72. Derzelle, S. et al. The PhoP/PhoQ two-component regulatory system of Photorhabdus luminescens is essential for virulence in insects. J. Bacteriol. 186 1270-1279 (2004).

73. Cowles, K. N., Cowles, C. E., Richards, G. R., Martens, E. C. \& Goodrich-Blair, H. The global regulator Lrp contributes to mutualism, pathogenesis and phenotypic variation in the bacterium Xenorhabdus nematophila. Cell. Microbiol. 9, 1311-1323 (2007).

74. Fedhila, S., Nel, P. \& Lereclus, D. The InhA2 metalloprotease of Bacillus thuringiensis strain 407 is required for pathogenicity in insects infected via the oral route. J. Bacteriol. 184, 3296-3304 (2002). Demonstrates the involvement of metalloprotease in the pathogenesis of $B$. thuringiensis.

75. Salamitou, S. et al. The plcR regulon is involved in the opportunistic properties of Bacillus thuringiensis and Bacillus cereus in mice and insects. Microbiology 146 2825-2832 (2000)

76. Titball, R. W., Hill, J., Lawton, D. G. \& Brown, K. A. Yersinia pestis and plague. Biochem. Soc. Trans. 31 , 104-107 (2003).

77. Waterfield, N. R., Wren, B. W. \& Ffrench-Constant, R. H. Invertebrates as a source of emerging human pathogens. Nature Rev. Microbiol. 2, 833-841 (2004).

78. Grenier, A. M., Duport, G., Pages, S., Condemine, G. $\&$ Rahbe, Y. The phytopathogen Dickeya dadanti (Erwinia chrysanthemi 3937) is a pathogen of the pea aphid. Appl. Environ. Microbiol. 72, 1956-1965 (2006).

79. Dillon, R. J. \& Dillon, V. M. The gut bacteria of insects: nonpathogenic interactions. Annu. Rev. Entomol. 49, 71-92 (2004)

80. Eleftherianos, l. et al. Prior infection of Manduca sexta with non-pathogenic Escherichia coli elicits immunity to pathogenic Photorhabdus luminescens: roles of immune-related proteins shown by RNA interference. Insect Biochem. Mol. Biol. 36, 517-525 (2006).

81. Tzou, P., Reichhart, J. M. \& Lemaitre, B. Constitutive expression of a single antimicrobial peptide can restore wild-type resistance to infection in immunodeficient Drosophila mutants. Proc. Natl Acad. Sci. USA 99, 2152-2157 (2002)

82. Dimopoulos, G. Insect immunity and its implication in mosquito-malaria interactions. Cell. Microbiol. 5 , 3-14 (2003)

83. Evans, J. D. et al. Immune pathways and defence mechanisms in honey bees Apis mellifera. Insect Mol. Biol. 15, 645-656 (2006).

84. Zou, Z et al Comparative genomic analysis of the Tribolium immune system. Genome Biol. 8, R177 (2007).

85. Kanost, M. R., Jiang, H. \& Yu, X. Q. Innate immune responses of a lepidopteran insect, Manduca sexta. Immunol. Rev. 198, 97-105 (2004).

86. Ryu, J. H. et al. Innate immune homeostasis by the homeobox gene caudal and commensal-gut mutualism in Drosophila. Science 319, 777-782 (2008). Describes changes in the commensal community by modification of host innate immune homeostasis and protection from ingested pathogens by the microbiota.

87. Shirasu-Hiza, M. M. \& Schneider, D. S. Confronting physiology: how do infected flies die? Cell. Microbiol. 9. 2775-2783 (2007).

Characterization of the colonization process of Naucoris by M. ulcerans.

88. Marsollier, L. et al. Protection against Mycobacterium ulcerans lesion development by exposure to aquatic insect saliva. PLoS Med. 4, e64 (2007).

89. Marsollier, L. et al. Colonization of the salivary glands of Naucoris cimicoides by Mycobacterium ulcerans requires host plasmatocytes and a macrolide toxin, mycolactone. Cell. Microbiol. 7, 935-943 (2005).

90. Marsollier, L. et al. Aquatic insects as a vector for Mycobacterium ulcerans. Appl. Environ. Microbiol. 68, 4623-4628 (2002)

91. Marsollier, L. et al. Impact of Mycobacterium ulcerans biofilm on transmissibility to ecological niches and Buruli ulcer pathogenesis. PLoS Pathog. 3, e62 (2007). 
92. Brennan, C. A. \& Anderson, K. V. Drosophila: the genetics of innate immune recognition and response. Annu. Rev. Immunol. 22, 457-483 (2004).

93. Lemaitre, B. \& Hoffmann, J. The host defense of Drosophila melanogaster. Annu. Rev. Immunol. 25 697-743 (2007).

94. Foley, E. \& O'Farrell, P. H. Nitric oxide contributes to induction of innate immune responses to Gramnegative bacteria in Drosophila. Genes Dev. 17, 115-125 (2003).

95. Dijkers, P. \& O'Farrell, P. H. Drosophila calcineurin promotes induction of innate immune responses. Curr Biol. 17, 2087-2093 (2007).

96. Uvell, H. \& Engstrom, Y. A multilayered defense against infection: combinatorial control of insect immune genes. Trends Genet. 23, 342-349 (2007).

97. Kocks, C. et al. Eater, a transmembrane protein mediating phagocytosis of bacterial pathogens in Drosophila. Cell 123, 335-346 (2005).

98. Cerenius, L. \& Soderhall, K. The prophenoloxidase activating system in invertebrates. Immunol. Rev. 198, 116-126 (2004)

99. Gillespie, J. P., Kanost, M. R. \& Trenczek, T. Biological mediators of insect immunity. Annu. Rev. Entomol. 42 611-643 (1997)

100. Hurst, G. D. \& Jiggins, F. M. Male-killing bacteria in insects: mechanisms, incidence, and implications. Emerg. Infect. Dis. 6, 329-336 (2000).

101. McGraw, E. A. \& O'Neill, S. L. Wolbachia pipientis: intracellular infection and pathogenesis in Drosophila. Curr. Opin. Microbiol. 7, 67-70 (2004).

102. Dobson, S. L. et al. Wolbachia infections are distributed throughout insect somatic and germ line tissues. Insect Biochem. Mol. Biol. 29, 153-160 (1999).

103. Bourtzis, K., Pettigrew, M. M. \& O'Neill, S. L. Wolbachia neither induces nor suppresses transcripts encoding antimicrobial peptides. Insect Mol. Biol. 9, 635-639 (2000)

104. Min., K. T. \& Benzer, S. Wolbachia, normally a symbiont of Drosophila, can be virulent, causing degeneration and early death. Proc. Natl Acad. Sci. USA 94, 10792-10796 (1997).

105. Priest, F. G. in Entomopathogenic Bacteria: From Laboratory to Field Application (eds Charles, J.-F. Delécluse, A. \& Nielsen-LeRoux, C.) 1-22 (Kluwer Academic Publishers, Dordrecht, 2000).
106. Bravo, A., Gill, S. S. \& Soberon, M. Mode of action of Bacillus thuringiensis Cry and Cyt toxins and their potential for insect control. Toxicon 49, 423-435 (2007).

107. de Maagd, R. A., Bravo, A., Berry, C., Crickmore, N. $\&$ Schnepf, H. E. Structure, diversity, and evolution of protein toxins from spore-forming entomopathogenic bacteria. Annu. Rev. Genet. 37, 409-433 (2003).

108. Schnepf, E. et al. Bacillus thuringiensis and its pesticidal crystal proteins. Microbiol. Mol. Biol. Rev. 62, 775-806 (1998).

109. Aronson, A. I. \& Shai, Y. Why Bacillus thuringiensis insecticidal toxins are so effective: unique features of their mode of action. FEMS Microbiol. Lett. 195, 1-8 (2001).

110. Peferoen, M. Progress and prospects for field use of Bt genes in crops. TIBTech, 173-177 (1997).

111. Hansen, B. M. \& Salamitou, S. in Entomopathogenic Bacteria: From Laboratory to Field Application (eds Charles, J.-F. Delécluse, A. \& Nielsen-LeRoux, C.) 41 64 (Kluwer Academic Publishers, Dordrecht, 2000).

112. Broderick, N. A., Raffa, K. F. \& Handelsman, J. Midgut bacteria required for Bacillus thuringiensis insecticidal activity. Proc. Natl Acad. Sci. USA 103, 15196-15199 (2006).

Demonstrates that commensal bacteria are required to kill gypsy moth upon $B$. thuringiensis infection.

113. Harada, H. \& Ishikawa, H. Experimental pathogenicity of Erwinia aphidicola to pea aphid, Acyrthosiphon pisum. J. Gen. Appl. Microbiol. 43 363-367 (1997)

114. Fedhila, S., Daou, N., Lereclus, D. \& Nielsen-LeRoux, C. Identification of Bacillus cereus internalin and other candidate virulence genes specifically induced during oral infection in insects. Mol. Microbiol. 62, 339-355 (2006).

115. Rolain, J. M., Franc, M., Davoust, B. \& Raoult, D. Molecular detection of Bartonella quintana B. koehlerae, B. henselae, B. clarridgeiae, Rickettsia felis, and Wolbachia pipientis in cat fleas, France. Emerg. Infect. Dis. 9, 338-342 (2003).

116. Bowen, D. et al. Insecticidal toxins from the bacterium Photorhabdus luminescens. Science $\mathbf{2 8 0}$ 2129-2132 (1998) Identification of Tc-toxins.
117. Morgan, J. A Sergeant, M., Ellis, D. Ousley, M \& Jarrett, P. Sequence analysis of insecticidal genes from Xenorhabdus nematophilus PMFI296. Appl. Environ. Microbiol. 67, 2062-2069 (2001).

118. Waterfield, N. R., Bowen, D. J., Fetherston, J. D., Perry, R. D. \& ffrench-Constant, R. H. The tc genes of Photorhabdus: a growing family. Trends Microbiol. 9, 185-191 (2001)

119. Charles, J. F., Silva-Filha, M.-H. \& Nielsen-LeRoux, C. in Entomopathogenic Bacteria: From Laboratory to Field Application (eds Charles, J. F., Delécluse, A. $\delta$ Nielsen-LeRoux, C.) 237-252 (Kluwer Academic Press, Dordrecht, 2000).

120. Daborn, P. J. et al. A single Photorhabdus gene, makes caterpillars floppy ( $m c f)$, allows Escherichia coli to persist within and kill insects. Proc. Natl Acad. Sci. USA 99, 10742-10747 (2002). Identification of the Mcf toxin.

Acknowledgements

The authors thank F. Leulier, N. Vodovar and C. NielsenLeRoux for helpful discussions and critical reading of the manuscript. Work described in this Review that was performed in our laboratories was supported by Centre National de la Recherche Scientifique (CNRS), Agence Nationale de la Recherche, the Schlumberger and Bettancourt Foundations, and the Association 'Vaincre la Mucoviscidose'

DATABASES

Entrez Genome Project: http://www.ncbi.nlm.nih.gov/sites/ entrez?db=genomepr

Bacillus cereus |Bacillus thuringiensis $\mid$ Mycobacterium

ulcerans | Photorhabdus luminescens | Pseudomonas

entomophila| Serratia marcescens $\mid$ Yersinia pestis

FURTHER INFORMATION

Bruno Lemaitre's homepages:

http://www.cnrs-gif.fr/cgm/immunity/enindex.html

http://lemaitrelab.epfl.ch

Frédéric Boccard's homepage:

http://www.cgm.cnrs-gif.fr/coli/index.html

ALL LINKS ARE ACTIVE IN THE ONLINE PDF 